University of Louisville

ThinkIR: The University of Louisville's Institutional Repository

Faculty Scholarship

6-1-2017

\title{
Is it safe to bring myself to work? Understanding LGBTQ experiences of workplace dignity
}

Kristen Lucas

University of Louisville, kristen.lucas@louisville.edu

Follow this and additional works at: https://ir.library.louisville.edu/faculty

Part of the Business Administration, Management, and Operations Commons

\section{Original Publication Information}

Baker, S. J., and Lucas, K. "Is it safe to bring myself to work? Understanding LGBTQ experiences of workplace dignity." 2017 Canadian Journal of Administrative Sciences, 34(2): 133-148.

This Article is brought to you for free and open access by ThinkIR: The University of Louisville's Institutional Repository. It has been accepted for inclusion in Faculty Scholarship by an authorized administrator of ThinkIR: The University of Louisville's Institutional Repository. For more information, please contact thinkir@louisville.edu. 


\section{Is it safe to bring myself to work? Understanding LGBTQ experiences of workplace dignity}

Sara J. Baker

Southern Connecticut State University

Kristen Lucas

University of Louisville

\section{ABSTRACT}

Despite increased efforts by more organizations to be seen as "gay-friendly," workplaces remain challenging sites for LGBTQ employees to navigate. We examine the ways in which LGBTQ employees experience dignity threats in the workplace and the protection strategies they use to deflect those threats. Interviews with 36 LGBTQ working adults revealed that their dignity is threatened by a range of identity-sensitive inequalities that undermine their safety and security when they claim authentic gendered/sexual identities. Specific safety and security threats to dignity include social harm, autonomy violations, career harm, and physical harm. To (re)claim their dignity, they engage in four primary dignity protection strategies: avoiding harm by seeking safe spaces, deflecting harm with sexual identity management, offsetting identity devaluations by emphasizing instrumental value, and creating safe spaces for authenticity and dignity.

Keywords: authenticity, gay-friendly, heteronormativity, safety, sexual identity management, workplace dignity

While disrespectful communication plagues many employees on a daily basis, problematic exchanges may be even more pervasive or severe for individuals who perform their gender, sex, and sexuality in ways that differ from heteronormative expectations. Lesbian, gay, bisexual, trans, and queer (LGBTQ) employees often are met with messages and experiences that are particularly damaging-including, but not limited to such things as bullying (Cowan, 2007; Hunt \& Dick, 2008), discrimination (Bedgett, Lau, Sears, \& Ho, 2007; Lewis, 2006, 2009; Ozturk, 2011; Sears \& Mallory, 2011), harassment (Bedgett et al., 2007; Das, 2009; Meyer, 2009), hurtful jokes and taunts (Baker, 2010; Silverschanz,
Cortina, Konik, \& Magley, 2008), and ostracism (Embrick, Walther, \& Wickens, 2007).

We explore the experiences of LGBTQ people in the workforce through a workplace dignity lens. Specifically, we identify the unique dignity threats LGBTQ working adults experience because of their gender and sexuality. We then describe the dignity protection strategies LBGTQ employees use to deflect threats. By viewing these experiences through a workplace dignity lens, we draw attention to the complexity of dignity negotiations as related to marginalized and stigmatized social identities. 


\section{The Gay Unfriendly Workplace}

The term "gay-friendly" has become a catch-all label for environments where LGBTQ individuals feel accepted (Giuffre, Dellinger, \& Williams, 2008). Workplaces have been designated as gay-friendly based on equal employment opportunity policies, the availability of employment benefits (e.g., partner benefits, trans*inclusive health care), demonstrations of organizational LGBT competency (e.g., training, resources, employee group or diversity councils), and public commitments to LGBT advocacy (e.g., employee recruitment, philanthropic support of LGBT organizations or events) (Human Rights Campaign, 2015). Despite these efforts to make organizations more inclusive and welcoming, workplaces remain largely gay unfriendly. In particular, LGBTQ employees can be harmed in the workplace by discrimination and sexuality-specific microaggressions.

For LGBTQ employees, workplace discrimination is marked by a lack of consistent formal policies and informal, prejudicial treatment that affects material outcomes including decisions about hiring, firing, job assignments, promotion opportunities, and fringe benefits (Lewis, 2009). For example, survey data revealed that one in four lesbian, gay, and bisexual employees reported experiencing employment discrimination, but for those who are out at work, the frequency increased to nearly one in three (Sears \& Mallory, 2011). Discrimination can bar LGBTQ employees from access to certain organizations and jobs. An ethnographic study of a large company in the United States revealed that $90 \%$ of respondents admitted they would not hire anyone they thought was gay, would not consider them the best or first choice for the position, and, if given the chance, would not rehire gay or lesbian employees already employed (Embrick et al., 2007). Once LGBTQ employees gain access to the workplace, they may have difficulty being promoted or maintaining secure employment. For instance, 7\% of LGB employees surveyed had lost a job due to their sexuality, while 9\% of LGB employees who are out at work reported losing a job due to their sexuality (Sears \& Mallory, 2011). Finally, LGBTQ employees experience discrimination in terms of equal pay and benefits. Between 10-19\% of LGB employees believe they were the recipients of unequal pay or benefits (Bedgett et al., 2007). These perceptions are not unfounded. In Canada, white, gay men with partners earn $5 \%$ less than heterosexual men with partners (Waite \& Denier, 2015), which is similar to the pay disparity in the US workforce (Pinsker, 2015).

Notably, LGBTQ employees can be harmed in the workplace whether or not they face overt and legallyactionable discrimination. They also may be harmed by repetitive, small injuries inflicted by microaggressions. Nadal (2008) described microaggressions as "brief and commonplace daily verbal, behavioral or environmental indignities” (p. 23) that are communicated as microassaults, microinsults, and microinvalidations (Sue, 2010). Nadal, Rivera, and Corpus (2010) outlined a taxonomy of seven common sexual orientation specific microaggressions: (a) use of heterosexist and transphobic terminology (e.g., calling an LGBTQ employee a "faggot," “dyke,” or “tranny”); (b) endorsement of heteronormative or gender-normative cultures/behaviours (e.g., implicit dress codes that align with birth sex); (c) assumption of universal LGBTQ experiences (e.g., stereotyping lesbian women as being "butch" or gay men as being into fashion or design); (d) exoticization (e.g., asking explicit questions about sex and genitalia); (e)

discomfort/disapproval with LGBTQ experience (e.g., believing that LGBTQ couples should not raise children); (f) denial of societal heterosexism or transphobia (e.g., a coworker telling an LGBTQ employee that they are being "overly sensitive" about discrimination); and (g) assumption of sexual pathology/abnormality (e.g., believing that all gay men have HIV/AIDS or are child molesters). In follow-up research, Nadal, Issa, Leon, Meterko, Wideman, and Wong (2011) added an eighth microaggression: denial of individual heterosexism/transphobia (e.g., saying "I have a gay friend" to refute accusations of homophobia).

Combined, workplace discrimination and the communication of sexuality-specific microaggressions paint a troubling picture of organizational life for LGBTQ employees. While organizations are increasingly implementing LGBTQ protection policies and seeking to create gay-friendly workplaces, there is certainly more work to be done in order for LGBTQ employees to achieve a full sense of workplace dignity.

\section{Workplace Dignity}

A valuable way to examine LGBTQ individuals' problematic experiences in the workplace is through the theoretical lens of workplace dignity. Workplace dignity is defined as "the ability to establish a sense of self-worth and self-respect and to appreciate the respect of others" (Hodson, 2001, p. 3) — that is, dignity is simultaneously highly personal and highly relational. Dignity is about one's own sense of self and the ability to maintain and protect that core part of being; at the same time, one's dignity is dependent upon others in order to be recognized. Moreover, the core principle of dignity is a fundamental belief that dignity is a universal and unconditional right of all human beings who possess, simply by virtue of being human, an inherent and equal value to all others (Lee, 2008). Because of its normative stance, dignity provides an important lens for understanding the experiences of people who experience challenges to their worthiness, esteem, and respect. A dignity framework is important for understanding LGBTQ experiences because it necessarily broadens the scope of attention from illegal and unethical behaviours that inflict harm to include behaviours that are necessary to affirm 
human value. While dignity spans all domains of life, it has particular significance in a workplace context.

From the perspective of employees, there is an expectation for inherent, earned, and remediated dignities (Lucas, 2015). However, these expectations are frequently violated. First, inherent dignity is the unconditional value accorded to individuals for the sake of being a human being (Sayer, 2007, 2011). It can be denied by disrespectful interaction or by being treated as a nonhuman object in a workplace context. Second, earned dignity is the conditional self-esteem and self-value that is derived from gaining recognition for efforts, skills, knowledge, and the like (Honneth, 1995; Islam, 2013). It can be undermined when people's competence and contributions go unrecognized or when opportunities to express their instrumental value are impeded. Third, remediated dignity is a negatively-valenced valuation based on injuries caused by organizational inequality and instrumentality, and which therefore calls for remedies of those injuries. It can be denied when social interactions and organizational practices exacerbate or draw unnecessary attention to the instrumental nature of the work relationship and inequalities embedded in the workplace (Lucas, 2015).

It is this latter category of dignity injury that is most salient for LGBTQ experiences of workplace dignity, as it highlights injuries grounded in inequalities. Sayer (2011) differentiated between two ways in which inequality is socially produced. The first is identity-indifferent inequality, which is the product of economic mechanisms. These inequalities include a variety of structural constraints inherent in the employment relationship, such as power imbalances deriving from internal hierarchies, unequal distribution of risk and rewards by occupational category, or differences in working conditions based on professional status (Crowley, 2012; Dufur \& Feinberg, 2007). The second is identity-sensitive inequality, which is a result of responses to certain (mis)construals of people's identities, such as through sexism, racism, ableism, homophobia, and the like. Sayer (2011) explains the unique problems of identity-sensitive inequality:

A crucial element in all these ills is treatment of members of the relevant groups in ways which are undignified: they may be mistrusted, their ability and probity may be doubted, they may not be taken seriously; worst of all, their vulnerability may be exploited, including the special vulnerability which derives precisely from their stigmatization. (pp 208209).

Research on identity-sensitive inequalities has examined issues of social class (Lucas \& Gist, 2015), gender (Crowley, 2013), and immigrant status (Stuesse, 2010). However, researchers have not yet attempted to understand experiences of workplace dignity as they relate to the identity-sensitive inequalities of sexuality. This omission is troubling because LGBTQ employees are particularly susceptible to dignity threats at work, as they are exposed to both identity-indifferent inequalities that arise from structural conditions of the employment relationship (which are experienced on par with working peers) and are vulnerable to further identity-sensitive inequalities because of (mis)construals of their sexual orientation. Therefore, we ask:

RQ1: What are the most salient dignity threats experienced by LBGTQ employees in the workplace?

Within the workplace dignity literature, there is a growing stream of research that examines individuals' responses to dignity threats. Some studies describe the resilience needed to persist in the face of dignity threats (Mears \& Finlay, 2005) or how social support can soothe dignity injuries (Kim, 2009); however, the primary focus has been on identity work and resistance.

The first cluster of responses to workplace dignity threats is identity work. Identity work refers to efforts individuals engage in to (re)create and maintain a positive, coherent, and preferred sense of self (Alvesson \& Willmott, 2002). Identity work can be undertaken at any time, but is often triggered by specific events, encounters, and experiences that threaten individuals' sense of self (Watson, 2008). In workplace dignity research, identity work tends to be prompted by stigma and is often linked to the performance of "dirty work" (e.g., assisting in abortion procedures, Chiappetta-Swanson, 2005; euthanizing animals, Sanders, 2010). But some identity work is in response to stigmatized social identities. For instance, Lucas (2011) described how blue-collar workers respond to threats tied to their social class identity by comparing highstatus and low-status outgroups. By claiming that people above them and below them in the social class hierarchy are equally deserving of dignity, they discursively construct an insulated centre space in which they can indirectly stake a claim for their own dignity. Other identity work is triggered by stigmatized affiliations. Otis (2008) illustrated how female hotel workers in China attempted to differentiate themselves from the sex workers who have an informal but thriving business linked to the hotel. The hotel employees maintained their dignity by engaging in a particular form of identity work couched in performances of professionalism.

The second cluster of responses to workplace dignity threats is resistance. Karlsson (2012) explained that when employees are exposed to negative conditions that undermine their worth, they are likely to respond by taking steps to restore their dignity or to retaliate against the organization for harming their dignity. Previous workplace dignity research demonstrates a range of resistance strategies such as unionizing (Stuesse, 2010), articulating cynicism against management (Fleming, 2005), quitting (Cleaveland, 2005), sabotage (Hodson, 2001), and engaging in counterproductive work behaviours (Lucas, Manikas, Mattingly, \& Crider, 2017). 
Notably, identity work and resistance have received considerable scholarly attention in LGBTQ research. To begin, identity work-particularly sexual identity management-is one of the most heavily researched phenomena in LGBTQ studies. Because sexual orientation can be invisible (in comparison to more visible social identities such as race), it enables some LGBTQ employees to make strategic decisions about whether, when, and/or how to disclose their identity (Clair, Beatty, \& MacLean, 2005). Usually decisions follow from a conscious costbenefit analysis that weighs the threat of stigma against concerns of authenticity and legitimacy (Clair et al., 2005) as well as overall organizational safety as evidenced by official organizational policies and informal coworker communication (Compton, 2016).

Even in situations when employees are "out" at work, they still may have to engage in sexual identity management. For instance, some may cover their identity. In covering, individuals "tone down" particular aspects of their identity that, while formally tolerated, are still not fully accepted or embraced within the mainstream (Yoshino, 2006). Rumens and Kerfoot (2009) described the strategies of dress and comportment that gay men engaged in to be viewed as "professional," as defined and constrained by heteronormative standards (see also Barrett, 2002, for coverage of women's gendered identity negotiation in a hypermasculine organization). Others may be out at work, but cover their sexuality by not inviting their partners to work parties or talking openly about them in casual conversations. For those individuals who choose to reveal or claim an LGBTQ sexual identity, the process of disclosing that identity still involves sexual identity management as it draws upon strategies of signalling, normalizing, and differentiating (Clair et al., 2005).

In addition to sexual identity management, resistance by LGBTQ employees is also an important area of scholarly inquiry. In fact, much resistance is inextricably intertwined with identity work: identity work (particularly that which claims a marginalized identity) can in itself be an act of resistance. But resistance may also require revealing an LGBTQ identity or, at a minimum, may signal an LGBTQ identity. For example, although they were not specifically studying workplace dignity, Creed, DeJordy, and Lok (2010) explored the ways in which LGBT ministers engaged in productive resistance to address the marginalization of LGBT people within their institutions. Through embodied identity work, these ministers were able to fuse the prestige of their occupational role with advocacy for LGBT-rights based equality. Studies such as this one demonstrate that LGBTQ people have the potential to become change agents within their respective organizations. Furthermore, Clair et al. (2005) identified maintaining self-esteem and generating social change as key personal motives determining strategies of revealing or concealing invisible stigmatized identities.
Given that maintaining self-esteem can be achieved, in part, through the sexual identity management strategies of passing, covering, or claiming (depending on the particular context), and that social change is often achieved through resistance, there is a range of possible responses to LGBTQ-based workplace dignity threats. Therefore, to gain a complete picture of how LGBTQ respond to dignity threats, we ask:

RQ2: What strategies do LGBTQ employees practice to protect their dignity at work?

\section{Method}

For this study, we took an interpretive-critical approach to examine LGBTQ employees' experiences regarding workplace dignity. In this section, we discuss the: (a) participants, (b) data collection, and (c) data management and analysis.

\section{Participants}

Participants were recruited through a sampling methodology that included internet outreach, contact with local, regional, and national LGBTQ interest groups, and participant referrals. Recruitment resulted in interviews with 36 LGBTQ working adults from the United States, representing a diverse range of organizational affiliations: education, for-profit, nonprofit, and government work. Participants ranged in age from 23-59, with an average age of 39. The majority of participants identified as gay men ( $n$ = 27), but other participants identified as queer women, bisexual, lesbian, gay woman, queer, pansexual, and trans. Most of the participants identified as white $(n=32)$.

\section{Data Collection}

In-depth, semistructured interviews were conducted with each participant. Questions focused on: (a) experiences of dignity at work (e.g., defining dignity, describing times when they experienced dignity at work, describing times when their dignity was threatened, and discussing their response to dignity threats), (b) perceived relevance of gender, sex, and sexuality in their workplace, and (c) sexual identity management strategies they employed on the job. Interviews were held at the location most convenient for participants. The majority were conducted face-to-face $(n=22)$, while the rest were conducted through Skype $(n=2)$ or by phone $(n=12)$. All formats revealed equally rich data. Interviews averaged 40 minutes each for a total of 28.25 hours of recorded talk.

Interviews were transcribed using a near verbatim approach, capturing the exact words that participants used but omitting vocal disfluencies (e.g., um, uh). After transcription was complete, the transcripts were reviewed to 
ensure accuracy, replace names with pseudonyms, and conceal any additional identifying information. In total, we have 233 pages of single-spaced text transcriptions.

\section{Data Analysis}

The first step of the thematic analysis was open coding (Rubin \& Rubin, 2005). We started this process by coding "chunks" (e.g., whole responses to each question on the interview protocol), using a qualitative data analysis program (Atlas.ti) to assist with coding and retrieval. The research questions as well as new codes that emerged from the data guided the coding scheme. We also wrote theoretical memos throughout the open coding process. We assigned at least one code to every chunk of data in the transcriptions. This resulted in 122 open codes.

For the second step we engaged in axial coding to make sense of the open codes in such a way as to clarify and summarize key concepts and themes (Rubin \& Rubin, 2005). We began this process by systematically examining the open codes and grouping them into higher-order categories. We made this move from open to axial coding by creating code families in Atlas.ti. Code families allowed us to group a series of open codes together and look at responses in conversation with one another.

Once code families were in place, we processed the data by looking for semantic relationships among the codes (Spradley, 1979). We examined each code family by looking for patterns, connections, and contradictions, which enabled us to collapse similar codes and eliminate redundancies. As we processed the data, we went back on numerous occasions to revisit participants' stories in a more holistic manner. We read through interview transcripts, reviewed questions, and returned to memos. We also held a data session to discuss emerging themes. We reviewed the content of participant's quotations, tested the accuracy of the codes, examined relationships between codes, refined themes, and created strategies for continuing the analytical process.

\section{Dignity Threats}

In this section, we identify the dignity threats experienced by LGBTQ employees in the workplace. In response to the query, What does dignity mean to you?, authenticity and safety/security emerged as the two most prominent meanings. Moreover, these two themes frequently occurred in tension with one another. For instance, Sam, a gay woman who works as a college instructor, discussed authenticity and safety as critical facets of dignity:

Feeling accepted and feeling safe. Feeling that I can be authentically [emphasis added] myself. That I can talk openly about myself and my life. That it will be accepted. There won't be any like weird faces, nonverbals, or I'll be verbally attacked. The word safety keeps coming to mind.
Dylan, a gay male college professor, had a similar response:

When you say dignity at work, I guess what comes to mind to me would be a respectful and supportive environment. That's really what I would associate with dignity at work. You don't feel like you have to censor yourself, you can be who you are [emphasis added], and you don't have to worry [emphasis added] about those sorts of things.

Falon, a self-described "aging gay male" who worked as an auto mechanic, also described dignity in connection to safety. For Falon, dignity was "not having to look over your shoulder. Not having to watch your back. No need for any fear [emphasis added]."

Throughout their interviews, participants shared stories that emphasized their interconnected — and often incompatible-concerns of authenticity and safety/security. They revealed that to protect themselves from dignity threats, they often had to sacrifice authenticity. But when they claimed authentic gendered/sexual identities at work, they were often susceptible to various kinds of harm. Below, we present four identity-sensitive dignity threats experienced by LGBTQ employees due to identitysensitive inequalities: (a) social harm, (b) autonomy violations, (c) career harm, and (d) physical harm.

\section{Social Harm}

The first major dignity threat LGBTQ employees experienced was social harm inflicted by disrespectful communication. Most definitions of dignity cite respect at its core, as well as the importance of being able to enjoy the respect of others. Sayer (2007) describes respectful interactions as more than "mere pleasantries," but instead as interactions that acknowledge the inherent worth of an individual. Therefore, people need respectful interaction from others to affirm their dignity. Moreover, when others actively and intentionally initiate disrespectful communication, the dignity of the targets is not only denied, but also injured with social harm. Social harm is more than just general incivility or hurt feelings; it is an injury that poses the risk of degradation of self-worth, wellbeing, and social standing. LGBTQ employees' dignity is particularly vulnerable to a range of identity-sensitive inequalities in treatment that can lead to social harm.

Nearly all participants described at least some level of disrespectful communication specifically due to their sexuality-whether it was at their current job or a previous one. Slurs, off-colour jokes, name calling, disparaging remarks about gender and sexuality, being the target of gossip, and ostracism were common. Some of the social harm was inflicted indirectly, such as when employees would overhear people using gay-phobic language (e.g., when a heterosexual 
customer defensively declared, "I'm not some sort of fag”), when coworkers used terms like "dyke" or "homo" to discredit people regardless of their sexual orientation, or lamenting that attractive men who are gay are "a waste.” It also occurred in us versus them language, such as when a conversation about a local high school whose band trip to Disney World coincided with Gay Day at the theme park, led one woman to blurt out in front of a gay coworker, "well gosh, I just don't think that I would want my daughter around them [emphasis added]."

Xavier, who worked as a financial analyst, described the social harm that occurred at his previous company. On his first day of work, he attended a meeting in which the manager opened with a joke:

I can't remember what the joke was exactly, but it started with "What's worse than a faggot with a chipped tooth?" And I thought "Oh my god. I have made the hugest mistake.” I couldn't believe it. The first thing I hear. I don't even remember what happened for the rest of the day.

Despite Xavier ultimately building a decent working relationship with the offending manager, the incident portended future problems involving disrespectful communication throughout the organization.

Most often, however, social harm was inflicted directly. For instance, Rory was working as a server in a restaurant when he first came out as gay. He explained that on his job "there was a lot of talk behind my back about me being so open about my sexuality and down the road it blossomed into a lot of outright disrespect and stuff like that.” A group of coworkers targeted him specifically:

They had a specific name for me, I don't know too much about Spanish, but they called me "Bonita," which was their term for pretty boy. But it was never really used in a nice, welcoming connotation. As soon as I would walk in the door that's what I heard.

Similarly, Charlie, now a hotel manager, recalled a troubling incident with a coworker:

Many years ago at another job, I had the head chef turn around and call me a "faggot." Very loudly, very outspoken and in front of about 15 other people. Very loudly with the total malice behind it too. My boss said "That's a problem between you two. That's not anything we have to deal with. You figure it out."

For Charlie, it was not only the chef's disparaging remark that inflicted social harm, but the fact that management would not address the problem with the offender, leaving him vulnerable to further abuse.

Harper, a social worker, described the mocking and ostracism he experienced after a coworker started sharing her suspicions that he was gay:
She told a bunch of people apparently that I was gay. It was kind of like night and day after that. People became really standoffish. Professional in the sense that we work together. But I was coming around the corner one time and [one of my coworkers] was talking to a couple of the other social workers and they were telling fag jokes. "Nah nah nah freaking fag” and whatnot. And I come around the corner and they were referring to me. I kind of stopped and they all shut up and went around into another room and started giggling.

Social harm was a real threat to dignity, self-worth, and well-being. Even years later, participants still painfully remembered these disrespectful interactions and the damage they inflicted.

\section{Autonomy Violations}

The second major dignity threat LGBTQ employees experienced was autonomy violations centering on employees' gender and sexuality. While some researchers position autonomy as the ability to exert control over one's own work domain (e.g., Crowley, 2014; Hodson, 2001), here we take Sayer's (2007) definition-to have control over one's life and for others to refrain from colonizing that life and to keep a respectful distance. In this sense, autonomy is also intrinsically linked to privacy. Participants indicated that their dignity was threatened when others in the organization encroached upon their autonomy, particularly regarding control over their private information and personal identity.

Phoenix, who describes herself as bisexual, regularly had her autonomy undermined by her supervisor when she worked as a college speech coach. She explained that her boss took issue with her sexuality and then began violating all boundaries of common decency:

My previous boss made it very vocal because of me being bisexual and identifying that way that I'm not really gay. I'm just with [my long-term female partner] until a decent penis come around. This was said on multiple occasions to students that were on our team competing, to faculty members, to friends at conferences. And I'm just like "what?"

The boss continued to heckle Phoenix about her sexuality, despite her explicitly asking him to "lay off.” At a work function, he talked so loudly about her sexuality that people at other tables started turning around to observe. He drove her to a strip club in an attempt to make her prove she was sexually attracted to women. The boss's behaviour is a clear example of violating one's autonomy and not keeping a respectful distance. He inappropriately concerned himself with Phoenix's sexuality by making declarations of knowing her sexuality better than she did, making crude comments about imagined future sexual encounters, and broadcasting these to others in a highly public way, despite Phoenix's protests. 
Another way LGBTQ employees are denied autonomy regards their decisions to stay closeted. Several of the participants in the study described efforts (some previous, some current) to remain closeted at work. For them, the fear of being outed against their will was a legitimate concern. Harper, who was outed by a coworker early in his career with detrimental consequences, attempts to remain closeted at work. However, he encountered a situation when a subordinate who was losing her job tried to leverage Harper's sexuality against him in order to keep her job. She had threatened to out Harper to their manager, believing that his sexuality would cause him to lose his job. While she never followed through with her plan, Harper was fearful that he was being denied the autonomy of making his own decisions to reveal or conceal private information about his sexuality.

\section{Career Harm}

The third major threat to LGBTQ employees' dignity was career harm inflicted by risks and limitations imposed due to their respective gender or sexuality. Establishing an instrumental value is a central component of dignity for all employees (Lucas, 2015). Therefore, it is necessary for people to have opportunities to demonstrate their competence, make meaningful contributions, and be recognized for their good work. However, in the case of LGBTQ employees, they were limited in their ability to do so because of their gender and/or sexuality. Threats ranged from fear of job loss, interference with work performance, and concerns about biased performance evaluations.

Most blatantly, some LGBTQ employees had legitimate fears of losing their job and their livelihood because of their gender or sexuality. Sometimes the risk was only perceived and sometimes it was real. After three summers working at an amusement park, Cameron had climbed his way up to a supervisory position and was responsible for processing daily cash transactions in the park. A friend of his who worked at the park confessed to Cameron that he had stolen a large amount of cash from the front gate. Cameron immediately called his manager to report the theft and then called his friend's supervisor. The friend asked for the day to tender his resignation; instead, he outed Cameron to management.

And that's when the big wigs found out. That's when the Director of Personnel and all the powers that be found out I was gay. Suddenly I went from a job where I was paying my way through college to where I was suddenly on suspension. I remember talking to [the Director of Personnel] and I remember it kept coming back to the gay issue. And I was like, "I talked to these people. Did I not insulate myself completely and do everything that I was supposed to?' And she was like, "Yeah, but you know it's the whole," and the gay issue kept coming up, the salaciousness of it. It kept cycling up over and over again. And finally I said, "Is that the problem?" And she was like "No, we have lots of gay people who work here.
They work in shows mostly.” I was simply in the wrong job, right?

The loss of Cameron's job had lasting effects. From an economic standpoint, his immediate loss of income slowed his degree progress and delayed his college graduation. But he also described a lingering fear for his career safety. "[Getting fired] left a legacy that was problematic. It did affect me as I went forward.. .. I was just perpetually, you know, just perpetually afraid that something horrible is going to happen.”

Another type of career harm occurred when others interfered with LGBTQ employees' ability do to their jobs. For example, Xavier experienced identity-sensitive interactions that negatively impacted his ability to do his job. When he eventually disclosed his sexuality at work, he "went from being the new senior financial analyst to the gay guy." Because he could not be fired for being gay, management "basically went above and beyond to try to make me so miserable that I would leave.” He explained one incident when he was excluded from an important work event:

There was going to be offsite training for a new software system that we had developed. It was an hour away. I had some coworkers come up to me and say, "How are you getting there tomorrow?" And I said, "How am I getting where?” They said, “An offsite training.” I knew nothing about it. They kept me completely out of the loop.

In addition to preventing Xavier from participating in all work functions - and therefore interfering with his ability to do his job-management also attempted to sabotage his career by filing negative performance reviews. Because of his consistent history as a top performer, Xavier was shocked to get a negative evaluation:

I got an official review from my manager saying that my work was poor, my work ethic was poor, everything opposite of anything I have ever heard said to me. I asked him to document all of this and he refused to document anything.

It quickly became clear to Xavier that his poor review did, in fact, result from discriminatory action against his sexuality.

I said to my manager, "The only reason why you are doing this right now is because I'm gay and you don't like it.” And he said, "I don't have a problem with,” and he couldn't get the word out-homosexuals. "I just never worked with one before." I said, "You never worked with one what?” And he just didn’t know what to say.

Unfortunately, these career injuries were not isolated incidents. Participants reported being fearful of getting fired, treated in ways that forced them to quit their jobs, counselled out of particular career choices, rated poorly on performance 
reviews, questioned on their ability to do their job properly or competently, and sabotaged at work. Therefore, identitysensitive dignity threats draw attention to real and perceived insecurities surrounding the workplace for LGBTQ employees.

\section{Physical Harm}

Finally, LGBTQ experienced dignity threats when their physical endangered due to their gender and sexuality. Bolton (2007) positioned safe and healthy working conditions as an essential element of working with dignity. In most workplace dignity research, safe and healthy working conditions relate to physical concerns of the worksite, such as heavy machinery, appropriate heating and cooling, absence of injuries, and a general safety culture (Apostolidis, 2005; Barrett \& Thomson, 2012). But even in workplaces deemed safe for the majority of employees, a big concern for LGBTQ employees was threats to their safety because of their gender, sex, and sexuality. One participant bemoaned, "People get killed for [disclosing LGBTQ sexuality]. There are real serious implications, serious potential for harm.”

When Walter came out at work, he became his city's first openly gay police officer. In addition to harassment and social ostracism, he faced numerous safety concerns that put his very life at risk. In an occupation where people rely heavily on their partners to deflect the inherent danger of the position, Walter was denied that support because of his sexuality:

People were afraid to ride with me. People didn’t respond and back up. There were a lot of things. I felt for my safety and well-being and the harassment that went on with that. . . [When I was on patrol I would] call for backup and backup wouldn't arrive or would be extremely late. Or if I was calling out information with the radio at that time people would cut into the radio transmission so all of my call would not be brought through. Therefore, all the information would not come through so I'd have to call it over and over again. That would be some of the things that would happen.

As an openly gay police officer, Walter was encountering dangerous situations on his own with no guarantee that his fellow officers would provide backup. When they did show up, it was purposefully late, leaving Walter in extremely precarious situations. And the threat of physical harm was real. Ten months after coming out at work, Walter was shot in the line of duty. It took two years to recover from his injuries and return to work. But the fear of physical safety followed him: "My first night on the job I was very fearful about what would happen. Were people going to respond or not? Was I going to get the support of my fellow officers?"

When Alex, who identifies as a queer person, worked night shift in a 24-hour pancake house, she experienced some targeted harassment from customers who had been high school classmates. The group of young adults regularly would come in and yell "fag" at Alex across the restaurant. Even though there were procedures for dealing with disruptive customers, those procedures were not put in place when it came to gay slurs. Instead the customers got to stay in the restaurant and continue their harassment.

It was odd because if anyone was yelling - even if they were yelling “cheese.” Let's say people came in, high school kids, and they started yelling "cheese" - we would kick them out. You can't just sit in a restaurant and yell "cheese.” There was something about it being "fag.". ... . But that was really, that was hard because it felt like that was okay [to yell gay slurs]. It was okay even when it wouldn't be okay for them to yell other things. That was disconcerting.

But for Alex, the taunting was more than social harm, as it also implied a targeted threat of physical harm. Alex, who had significant experience facing threats to their physical harm based on their gendered identity, concluded, "It also seemed like a safety issue, you know."

For Blake, a trans man who describes himself as a "faggy kind of guy," the threat of physical harm manifested itself in what his future conditions may be like in the workplace. In particular, Blake was concerned about the possible physical harm that could result from having a family, especially because he was intending to get pregnant and have a biological child. He described his family planning as "a huge source of anxiety.” As a college instructor, he was particularly concerned with how he would address the pregnancy with his department chair and his students. Moreover, he was concerned with how people would respond to seeing a "pregnant man."

That could put me in a really unsafe physical position to the point where I have a lie ready. I mean it's awful, but I picture being surrounded by a group of young bullies, like giant students who are like, "You are a pregnant man and we are here to kill you" or "We are going to beat you up." And me having this lie of "oh no, no. See, you know, I am pro-life and I was raped, and I am carrying this baby for Jesus Christ.” All of this is like not who I am whatsoever. . Just having this lie ready is kind of mortifying.

Beyond the threat of violence, Blake also faced another risk of physical harm. Without any precedent in his organization for dealing with trans* people who are pregnant, Blake is concerned that he may not get the medical care and other support needed to have a safe pregnancy. He says, "I worry that they won't take things seriously. Like, 'Oh, everything will be fine,' and that will put me at risk.”

Blake's concerns underscore an important issue regarding threats of physical harm. Even in the absence of actual 
physical harm, the basic threat of physical harm is psychologically damaging, as it reduces perceptions of safety and security that enable confident navigation of the respective context, imposes emotional distress, and demands ongoing vigilance. Safe and healthy working conditions are a basic need of working with dignity. But these stories show that workplace safety and security cannot be taken for granted by LGBTQ employees, particularly when they are targeted for their sexuality in ways that put them in harm's way.

\section{Dignity Protection Strategies}

In this section, we examine the strategies LGBTQ employees use to protect their dignity from the sexualityspecific threats identified above. These strategies are clustered into four main approaches: (a) avoiding harm by seeking safe spaces; (b) deflecting harm with sexual identity management tactics; (c) offsetting identity devaluations by emphasizing instrumental value; and (d) creating safe spaces for authenticity and dignity.

\section{Avoiding Harm by Seeking Safe Spaces}

The first protection strategy LGBTQ employees used was to avoid threats altogether by seeking safe spaces in which to work. For participants, seeking safe spaces was a strategic decision to position themselves in places where they could be "comfortable." One participant noted that seeking safe spaces was absolutely essential: “That's one of the only ways that in some states we can protect ourselves, by finding [safe spaces]. Get in where you fit in, find an employer where you are welcome." Safe spaces included organizations, industries, and cities.

One of the most common ways participants identified safe spaces was by carefully monitoring particular organizations during the interview process. They reported asking explicit questions about policies and benefits, searching publicly available information on company LGBTQ resources, and evaluating the organizational culture before taking a job offer. For example, Gael, a high school teacher, described the monitoring process as "protecting yourself”:

You need to know the policies of the places where you are going to be working. You need to know management. You need to know administration. You need to educate yourself and know what you are getting into. It's one thing to say, "Yes, that's wrong," but that doesn't make sure that you are going to have a positive work experience.

Where an organization was not deemed to be safe, participants sought work elsewhere. In other cases, the reputation of certain organizations prevented people from applying in the first place. Bailey, a public defender, was conscientious about organizational fit in her job search:
I wasn't going to go work for some super conservative, old boy network firm. I wasn't going to do that. I had a lot of biases and prejudice about what they were going to be like and I wasn't willing to deal with it. To some extent, I have opted myself out of a lot of stuff based on my belief-whether it is accurate or not-that these old institutions of traditionalism are not going to be supportive.

Some safe space seeking was accomplished by identifying LGBTQ-friendly occupations or industries, such as the arts, advertising, and academia. For instance, Gavin, who worked as an art museum director and taught part-time at a university, noted he worked in "a relatively safe space. It's never been an extraordinary thing for me to be gay in the academy or the museum world.” Likewise, Jordan noted that in the advertising and marketing industry, he has come to expect "the people who have hired me have encountered gays and lesbians before and they have been cognizant enough, professional enough, and considerate enough" to create policies that build safe and inclusive cultures. Several participants worked in the field of higher education, noting that academia was more inclusive and gay-friendly than other career paths. For example, Quinn adapted her career plans to find a safe occupation. In a discussion of the challenges faced by public school teachers, she explained, “that's why I decided to teach college. Initially, I wanted to teach high school, but once this kind of developed and I started exploring my own sexuality and gender, there's no way I could.”

Finally, participants sought out safe spaces geographically. Geographic safe spaces tended to include cities and geographic regions with a reputation for being more liberal. Dylan, a college professor, noted that he had to engage in a "multifaceted" evaluation process to choose his workplace. After coming out to (some of) his immediate family and being met with an unsupportive and threatening response, safety became "more prevalent and salient in terms of what [he] started to look for with a career.” He explained:

I eliminated small departments and small universities from the get go. I eliminated places that were out in Hicksville that I knew were likely to be places where I would have a greater likelihood of experiencing more confrontation and less support. I only applied at departments and institutions and places that were embedded within large to semi-large to large community environments. You know, cities, they tend to be somewhere where there is more liberalness and openness to diversity in terms of sexual orientation, identity, all that sort of stuff. I guess for me, I just made choices early on that would eliminate places where I would associate risk. 
Logan, an IT professional, described himself as "lucky" and credited much of his dignity to living in a US West Coast city that has a "robust" and "very healthy" gay community with a mix of vibrant and thriving industries.

He said:

I think part of it is geographic. We are in a city where there is a very large professional gay community. I tend to think that the policies of the company dictate acceptance and demand respect for all of their employees from the top of the company, all the way down.

Logan expressed concern that LGBTQ working adults in smaller cities or more conservative areas would not be afforded the same comfortable experiences that he enjoyed. He advised that LGBTQ individuals experiencing discrimination seek safer geographic spaces. "Maybe you should get out of Kansas and go to a place that is a little bit more accepting."

In summary, LGBTQ working adults were able to protect their dignity by proactively positioning themselves in career spaces that would present fewer potential threats and greater potential support. While this dignity protection strategy enabled them to avoid dignity threats, it did come with career limitations, as people turned down employment offers, stopped pursuing desired career paths, and limited themselves geographically. More importantly, just because they strategically chose safe spaces, it did not mean that they were fully protected. Participants remained vigilant to ongoing dignity threats and navigated workplaces with caution.

\section{Deflecting Harm with Sexual Identity Management}

The second strategy employees used to protect their dignity was to deflect threats as much as possible. Because LGBTQ dignity threats are identity-sensitive, people can avoid the threats by presenting an identity that is different from the targeted identity and therefore safe from associated inequalities of treatment. This strategy included attempts to pass as heterosexual (or at least not confirm an LGBTQ sexuality) and performing identities within the constraints of heteronormative discourses of professionalism.

One of the first line approaches to protecting dignity for LGBTQ employees then was engaging in the sexual identity management of passing as heterosexual or staying closeted. Although nearly all participants currently were out in the workplace, several of them recalled passing at earlier points in their career, specifically to avoid the harm inflicted by being LGBTQ, such as the person who said, "Years ago, everything I did was trying to protect my identity."

Participants who employed various passing tactics explained that fear of dignity threats was a salient consideration in their decision to stay closeted at work. For instance, Yancey, who is a manager at a manufacturing plant, is only out to people at work who he knows are also gay. Most other people in his company are unaware of his sexuality. His reason for staying (partially) closeted is because of his fear of not being respected:

I'm like, "If I came out to him [a coworker] what would he think?” But again, it's me putting my projections on other people and me worrying about not being respected. . . . They already don't treat me-some of them don't treat me-respectfully.

Therefore, because of his desire to avoid further social harm, Yancey is very careful in how he discusses his personal life:

If they ask me what I did this weekend and I was out the whole weekend with my boyfriend on a trip, I will say I went on a trip with friends or something like that. Sometimes I'll name the place or activity, but I won't say "with my boyfriend."

Similarly, Gael, who is a high school English teacher, attempts to pass in order to deflect dignity threats. He explains, "I find that to protect myself I find that I don't not talk about those things [personal life], but I will use gender nonspecific pronouns and stuff like that, the usual stuff." Others reported calling their partners or spouses "roommates" when engaged in conversation at work, distancing themselves from interactions that might elicit personal disclosures, carefully monitoring what they post to social media in case it could be seen by coworkers, and wearing a wedding ring (although not married) to lead to assumptions of having an opposite-sex spouse. Moreover, when making the decision to move from passing to coming out, protection from dignity threats remains a strong consideration. One participant said that his strategy was to "test the waters" by coming out slowly to one person and monitoring the response for cues as to how the organization will react. And Rory, who was enlisted in the US military during the Don't Ask, Don't Tell era, said that he also tested the waters:

[I am careful with information about my sexuality] especially when it comes to newer work, especially when I am trying to figure out how people feel about it. If it seems to be a macho environment, I definitely try to keep it quiet until I know more about the people.

The next major approach to deflecting identitysensitive threats is to downplay LGBTQ sexualities in ways that aligned within ideals of heteronormative professionalism. Even when employees were officially out at work, they still had a tendency to downplay LGBTQ sexualities as to not draw attention to themselves. Like the passing approach, the professionalism approach made people less of a target for identity-sensitive dignity threats. 
For example, while the majority of educators felt comfortable being out to their peers, they were much more guarded in the classroom and paid attention to things like dress and vocalics in order to conform to traditional gender/sex norms. For example, Sam described her personal and more authentic performance of gender as a more "masculine style" and "butch," typically dressing in a t-shirt and jeans. But when teaching, she assumes a more professional identity:

I wear lipstick. I wear full-on face makeup in my organization when I go to work, when I go to school. That's generally when I perform a more feminine style. I am generally laid back as a student. But when I am in class [as the instructor], I perform a more professional [emphasis added] look, more feminine with the makeup on.

Gay men made conscious efforts to manage their voices in ways that were more aligned with heteronormative expectations. Elliott described his voice as normally in the "high tenor range," but in the classroom he tried "very hard to teach at the lowest point" even though it was physically difficult for him to speak in a lower range. Isaac, an admissions counselor, also consciously adjusted his voice to present a more "straight" identity:

When I have a male student on the phone my voice deepens and I have a little bit of a more assertive approach. It's not conscious; it's just something that I had always done even when I was an admissions counselor myself. ... I was working with military students and I was having trouble connecting with these military guys so just having that deep voice, assertive, more typical masculine traits over the phone. I felt like that helped. And now my team will joke about it. There's another gay guy on my team and he's like, "Was that Straight Isaac I just heard talking to that student?” Yes, Straight Isaac had to make an appearance. It's not necessarily with every person. It depends on the situation.

In summary, participants engaged in various sexual identity management strategies to protect themselves from dignity threats. But whether individuals chose to pass as straight to avoid harm, to "cover" or downplay their sexuality to make it easier for heterosexual colleagues to accept and respect, or simply to engage in gendernormative performances that were misaligned with their authentic selves, their sexual identity management strategies came with tradeoffs for authenticity.

\section{Offsetting Identity Devaluations by Emphasizing Instrumental Value}

The third strategy employees used to protect their dignity was to offset the devaluation of their inherent worth by emphasizing their instrumental worth to the organization. In this way, they were able to affirm their dignity by focusing on ways in which the organization valued them. This strategy was enacted through filling roles as a valued token or by engaging in identity work and sensemaking that promoted their competence and contributions.

The valued token approach created spaces for LGBTQ employees' sexualities to become fully visible at work, particularly when their sexuality had some sort of instrumental value. For instance, Neal took on the role of a valued token when his company asked him to be the part of the recruitment team. As a member of this company-wide team, he helped recruit undergraduate and MBA students. However, one of his main tasks was to attend a national job fair for LGBTQ job seekers. As Neal explained:

You go out and answer questions for the company. We sponsored a lunch where people who were interested would sign up to come to our lunch. We were a sounding board for any of the questions. I did go through and interview people for internships and full-time positions from an MBA perspective. Obviously, they needed a gay man in finance. Now I don't know if I was the only one, but nonetheless I got the gig.

Even though Neal recognized that his sexuality played a part in being selected for the recruitment team, he still believed that the experience was a positive one, saying, "I took a lot of pride. I had dignity in being in charge of that." For Neal, dignity was equated with "respect and awareness from colleagues."

Another valued token role was to leverage sexuality for business ends. Riley regularly used this strategy with much success. As a teenager, he began patronizing gay-owned businesses. Within a few years, he had built a large professional network of gay business owners within his community. Later, when he opened his own construction company, he used his network to get jobs. Riley also used his sexuality in various sales positions he held. When he worked in a real estate agency, he gained an unlikely ally by connecting his sexuality to potential sales:

I've even had real estate brokers who would allow me to advertise in the [local gay paper]. I ask them first. I have to ask the broker first because it's his name in there. He said, "Riley, I don't care who you sell to. It doesn't matter to me.” He was very religious. I don't think he's $100 \%$ accepting. I think he saw dollar signs. He’s like, "I don’t care you can put my name in there.”

A similar situation occurred when Riley worked in automobile sales. After the sales manager learned that Riley was gay, they struck up a friendship tied, in large part, to their sales partnership. Riley said that when gay customers would come in to the dealership, the manager would be sure to match them for the sales call. Riley said, "he always put 
them [the gay customers] with me and I thought that had a lot of dignity."

LGBTQ employees did not have to fill a token role to emphasize their instrumental value. Some of this was done through identity work and sensemaking. That is, employees centered their energy on being excellent employees in hopes that the value of their competence and contribution would outweigh the stigma of their sexuality.

For example, Dylan - the professor who described dignity as not having to worry about being "who you are"-belied that sentiment by saying that his sexuality was not relevant in the context of work:

I think the issues come sometimes when we try to lead with a part of our identity that isn't that critical to our day to day job functioning. Maybe some people will disagree with me. They would say, "Oh my sexual identity is an important part of my work identity, of who I am.” But for me it simply is not.

This strategy of privileging instrumental contributions over personal identities was also evident in the advice that Dylan offered for younger LGBTQ individuals entering the workforce. He explained that it was important to first be seen as a valuable asset to the organization before sexuality could be brought into the conversation. Dylan explained:

Give people a reason to want to keep you around that has nothing to do with your sexual identity. Be a stellar worker. Show that you've got a phenomenal benefit to an organization and you have skills that can make it strong. What I think happens is when people get to know you and they know that you are a strong, good, reliable member of the organization it's very hard for them to uphold prejudices against you. Come to find out, "Oh Dylan is gay. Oh well, Dylan is great. That doesn’t matter.”

This focus on generating and emphasizing instrumental value was both a way to create a sense of workplace dignity and a possible way to deflect some of the threats LGBTQ employees might otherwise face. By being a strong performer with high instrumental value, employees believed that they were more immune to dignity threats. As such, the instrumental value strategy was a way to persist through difficult experiences.

\section{Creating Safe Spaces for Authenticity and Dignity}

The fourth strategy employees used to protect their dignity was to engage in resistance, advocacy, and support to create safe spaces for themselves and others to claim authentic sexual identities at work. Again, safety was a significant concern for LGBTQ employees. When asked what advice they had for a young LGBTQ person just embarking on their career, more than half specifically shared advice on how to seek safe spaces - carefully studying organizational culture and climate, asking about specific policies and protections, listening more than talking, being careful about becoming friends too quickly with people at work, seeking allies, not "going around and acting in a gay manner," staying quieted and closeted until they are sure it is safe to come out, and choosing occupations, companies, and cities that will offer the greatest protections.

But once people were safe, there was for some a commitment to use that position of relative safety to create spaces that are safe for others to claim authentic gendered and sexual identities. Cameron, an educator and an LGBT campus group advisor, cautioned young people to "be smart" about their sexuality in the workplace. But he had different advice for older people:

But I'm an old man and I don't care anymore. And a young person-as I was a young person once-can lose a whole lot in an instant. It can have long term effects so that's what I would tell a young LGB [to "be smart"]. For an LGB person my age, I would tell them to get off their fucking ass and be who you are and make sure it's the safest place it can be for the young people coming in behind them. And that's why I'm here [in my job] in the first place.

Others who shared Cameron's sentiment, protected their dignity and others' dignity by becoming change agents. They engaged in what Creed and Scully (2011) described as encounters, "pivotal moments in a larger process whereby beliefs about and attitudes toward an identity are mediated and altered and discriminatory workplace policies and practices are challenged” (p. 409).

For instance, while working as a church music director, Elliott found it important to publicly express his identity as a gay man when his church was debating the inclusion of openly LGBT pastors. The pastor and leadership from his congregation held several meetings to discuss the upcoming vote and answer questions. Elliot said that he made it "a point" to attend all of the meetings. He explained:

My comment is to say if someone wants to stand up and say that they hate gay people, I think that there should be a gay person in the room. If that's your opinion you are welcome to say it, but if you are not willing to say it to my face you should rethink your opinion.

For Elliott, like so many other participants, dignity was equated with respect and it was important for members of the congregation and church leadership to see him as a gay man in addition to his role as the music director.

Other participants engaged in productive resistance for the purposes of destabilizing the heteronormative and homophobic status quo. For Logan, who worked in the information technology industry, dignity was about "having acceptance and equality. To think that my husband is treated 
in the exact same way as if I had a wife.” So when Logan put a picture of his husband on his desk he was seeking dignity at work through acceptance and equality. Instead, some in the organization saw it as an act of disruption:

My first day on the job, I got to my desk and put out a picture of my husband. Of course everybody came by and said, "Oh, is that your brother?” And I was like, "No that's my husband." There were some very religious people there who took offense to it and had actually asked one of my supervisors, coworkers, to take it down because it was offensive.

Despite his coworkers' claims of offense, Logan left the picture on his desk. His explained that he wasn't the only gay person on the floor at the time. Logan felt like he needed to take a stand and leave the picture up to show solidarity with other LGBT employees. Logan said:

It was validating that those who were gay and lesbian had come up and said, “Oh my god. I can’t believe you left that up. That's fantastic.”.... A lot of people would say, "It's your first day on the job. Don't you think that it should be about your performance not your sexuality?” I looked at it as, "No, this is my work environment and if I can't be comfortable in my work environment then I don't want to be in this environment." I tend to think that people may not be as accepting because they think they haven't met anyone. There are 5 or $10 \%$ of us on the floor who were gay. Then those who think that gays and lesbians are only in the corners or whatever their preconceptions are, you challenge them by being out, open, and honest, comfortable and well adjusted.

The strategy of creating safe spaces presented an opportunity for LGBTQ employees to contribute to the creation of workplaces that enabled the attainment of dignity in the workplace for themselves and for others. While this strategy enabled (and required) the most authenticity, it also was the one that put people at the greatest risk of immediate dignity threats. Also, it is worth noting that in order to engage in this strategy, people usually had some level of security — whether that was economic security, other career options, a strong sense of self, or even a feeling of "nothing left to lose." Therefore, people who were the most vulnerable may not have the opportunity to do the work that would create the most longterm benefit.

\section{Summary}

This study examined the relevance of marginalized and stigmatized social identities in the workplace and, more specifically, the negotiation of gender, sex, and sexuality. Through our qualitative investigation, we identified dignity threats experienced by LGBTQ employees and the strategies they used to protect themselves from those threats. Interwoven throughout are challenges of safety and authenticity in the workplace.

First, we demonstrated that LGBTQ employees experience identity-sensitive inequalities due to their gender and/or sexuality that threatened their dignity. Threats were communicated through interactions or conditions that undermined their sense of self-worth and self-respect and often denied them respect from others, including social harm, autonomy violations, career harm, and physical harm. Then, faced with these threats, LGBTQ employees engaged in a variety of strategies to protect their dignity. Some avoided dignity threats by seeking safe spaces, whether that was picking safe organizations, industries, or communities. Some deflected dignity threats through sexual identity management strategies that concealed or downplayed their LGBTQ gender and/or sexuality. Some emphasized their instrumental value (for which their dignity was affirmed) while dismissing the importance of identity-based devaluations. Yet others, when they determined it was relatively safe to do so, acted as change agents to create safe spaces for themselves and others to claim their authentic gendered and sexual identities.

\section{Contributions to Scholarship}

Overall, this project makes important theoretical contributions. First, we contribute to research on dignity and identity in the workplace. By examining the experiences of LGBTQ employees, this study continues to draw attention to social inequalities that persist in the workplace (Sayer, 2007). We add to dignity theory by showing that LGBTQ people experience unique dignity concerns that go beyond identity-indifferent indignities embedded in employment relationships. Whereas previous research on dignity and social identity has shown that employees who possess marginalized social class identities may feel threatened by what they do being undervalued (Lucas, 2011), here we find that LGBTQ employees feel threated by who they are placing them at risk of harm. Additionally, while safety has been noted in previous dignity theorizing (Bolton, 2007), LGTBQ dignity threats show that there are unique contours to their meanings of safety. Safety is not just about preventing job-related physical injuries, but it is about keeping bodies, minds, spirits, privacy boundaries, and relationships safe from identity-sensitive inequalities.

Second, this study makes important contributions to LGBTQ studies. A workplace dignity framework is important because it is based on the principle that all humans have an inherent and equal value. Therefore, when LGBTQ people experience harm to their self-worth, selfvalue, and well-being, it is no longer an issue of incivility, hurt feelings, or discrimination. Instead, a dignity framework draws attention to identity-sensitive inequalities being a direct violation of ethical and moral standards.

Also, using a workplace dignity lens to study the experiences of LGBTQ employees is important because it 
rhetorically shifts the conversation away from shame and focuses attention on positive value to which individuals are entitled.

A workplace dignity framework also enabled us to position identity-sensitive dignity threats as the context and motivation for a variety of self-protective behaviours. This approach brings into focus LGBTQ employees' agency and strategic efforts in the quest for upholding dignity. Namely, we show that individuals protect their dignity by controlling themselves (sexual identity management; sensemaking about instrumental value) and their environments (seeking safe spaces for themselves; making spaces safer for themselves and others). Yet, we also reveal the inadequacy of sexual identity management in protecting dignity, particularly for those individuals with nonheteronormative gender expression or for those who experience threats of being outed by others. Consequently, LGBTQ employees must have access to multiple strategies for protection if they are to be successful in (re)claiming their dignity at work. Moving beyond the discussion of revealing or concealing sexuality, then, we can demonstrate that those people who pass, those who cover their identities to appease others, and those who resist are all motivated by a common goal: to protect their fundamental and inherent human value. As such, we contribute to the scholarly conversation on invisible social identities (Clair et al., 2005), passing (DeJordy, 2008), and covering (Yoshino, 2006).

\section{Applied Implications}

A discussion of the role of dignity presents practical applications for fostering cultures of respect and inclusivity in the workplace through the promotion of advocacy encounters (Creed \& Scully, 2011). This type of encounter draws attention to injustice and calls for action. We suggest that dignity can serve as a productive way for LGBTQ groups to engage in advocacy encounters. Several participants mentioned the importance of having such a group within their organization. At times, other participants mentioned that these groups were no longer needed in the organization, but had in the past played an important role in sparking positive change. LGBTQ groups can use the discussion of dignity as a way to draw attention to the heteronormative nature of work. For instance, the communication of microaggressions could be phrased as an issue of dignity at work possibly mitigating the impact of particular religious or personal beliefs about LGBTQ sexualities. This moves the conversation from just being about binaries of gender, sex, and sexuality to recognizing the inherent worth of every human being and the importance of communicating that respect in the workplace. This conversation could be extended to invite solidarity across a multitude of nondominant identities in the workplace and to help unite people across lines of not only gender, sex, and sexuality, but race, ethnicity, class, religion, (dis)ability, and other forms of difference.

\section{Limitations and Future Research Directions}

The study is limited in the lack of diversity within the sample. The sample primarily reflects the voices of cisgendered gay men with lesser representation from lesbian, bisexual, and trans* individuals. Participants also were disproportionately white-collar and highly educated, which likely influenced the kinds of threats they encountered and the range dignity protection strategies available to them. Therefore, to fully understand LGBTQ workers' experiences of workplace dignity, future research in this area must do a better job of capturing the diversity of experience by including voices from lesbians and bisexual people, and from individuals with queer and trans identities. Also, future research should query workers who are representative of the working population as a whole, especially those in blue-collar and service industries whose dignity threats may be further complicated by intersections of material and class-based inequalities.

A second limitation of this research is that the stories and experiences that are captured are retrospective in nature. Therefore, it raises several questions-from the accuracy of recollections of specific dignity threats (are participants remembering incidents incorrectly?), to biases within the recollections (are they making problematic assumptions about others' motivations or perceiving threats that were unintended?), to the current relevancy of particular kinds of threat (are they recalling problems that are no longer issues in today's workplace?). On one hand, because dignity is personally experienced and judged and because sensemaking is retrospective by its very nature, a retrospective approach was necessary in this study. But on the other hand, there are research strategies that could add to the trustworthiness of the findings. Future research could include different kinds of data collection that could get at more current experiences of (in)dignities at work. For instance, diary studies could be one way of accessing current stories. Alternatively, an extended ethnographic study of a single organization with several LGBTQ employee-participants might provide opportunities for triangulation (e.g., focus groups with LGBTQ employees, interviews with the HR department, document analysis, and cultural observations), which could point to salient dignity threats (and affirmations) and dignity protection strategies as experienced (almost) in the moment.

\section{Conclusion}

The goal for this project was to use a workplace dignity lens to understand the experiences of LGBTQ employees. The workplace can be a difficult space for LGBTQ employees to navigate, particularly when they limit their safety and authenticity. The lived experiences of these participants provide a catalyst for a larger conversation regarding the dignity of LGBTQ persons in the workplace. It is our hope 
that by having a deeper understanding of how LGBTQ employees' dignity is threatened, workplaces can become more inclusive and respectful environments that make it safe for everyone to bring themselves to work.

\section{References}

Alvesson, M., \& Willmott, H. (2002). Identity regulation as organizational control: Producing the appropriate individual. Journal of Management Studies, 39, 619-644. doi:10.1111/1467-6486.00305

Apostolidis, P. (2005). Hegemony and hamburger: Migration narratives and democratic unionism among Mexican meatpackers in the U.S. West. Political Research Quarterly, 58, 647-658. doi:10.1177/106591290505800412

Baker, S. J. (2010). Exploring the dimensions of gay taunting. Paper presented at the National Communication Association annual conference, San Francisco, CA.

Barrett, F. J. (2002). Gender strategies of women professionals: The case of the US Navy. In M. Dent \& S. Whitehead (Eds.), Managing professional identities: Knowledge, performativity and the 'new' professional (pp. 157-173). London, UK: Routledge.

Barrett, J., \& Thomson, L. (2012). Returning dignity to labour: Workplace safety as a human right. New Zealand Journal of Employment Relations 37, 82-89.

Bedgett, M. V. L., Lau, H., Sears, B., \& Ho, D. (2007). Bias in the workplace: Consistent evidence of sexual orientation and gender identity discrimination. Los Angeles, CA: The Williams Institute.

Bolton, S. C. (2007). Dignity in and at work: Why it matters. In S. C. Bolton (Ed.), Dimensions of dignity at work (pp. 3-16). Oxford, UK: Butterworth-Heinemann.

Chiappetta-Swanson, C. (2005). Dignity and dirty work: Nurses' experiences in managing genetic termination for fetal anomaly. Qualitative Sociology, 28, 93-116. doi:10.1007/s11133-005-2632-0

Clair, J. A., Beatty, J. E., \& MacLean, T. L. (2005). Out of sight but not out of mind: Managing invisible social identities in the workplace. Academy of Management Review, 30, 78-95. doi:10.5465/amr.2005.15281431

Cleaveland, C. (2005). A desperate means to dignity: Work refusal amongst Philadelphia welfare recipients. Ethnography, 6, 35-60. doi:10.1177/1466138105055656

Compton, C. A. (2016). Managing mixed messages: Sexual identity management in a changing U.S. workplace. Management Communication Quarterly. doi:10.1177/0893318916641215

Cowan, K. (2007). Living together: British attitudes towards lesbian, gay, and bisexual people in 2012. London, UK: Stonewall.

Creed, W. E. D., \& Scully, M. (2011). Songs of ourselves: Employees' deployment of social identity in workplace encounters. Journal of Management Inquiry, 20, 408-429. doi:10.1177/1056492611432810

Creed, W. E. D., DeJordy, R., \& Lok, J. (2010). Being the change: Resolving institutional contradiction through identity work. Academy of Management Journal, 53, 1336-1364. doi:10.5465/AMJ.2010.57318357
Crowley, M. (2014). Class, control, and relational indignity: Labor process foundations for workplace humilation, conflict, and shame. American Behavioral Scientist, 58, 416-434. doi:10.1177/0002764213503335

Crowley, M. (2012). Control and dignity in professional, manual and service-sector employment. Organization Studies, 33, 1383-1406. doi:10.1177/0170840612453529

Crowley, M. (2013). Gender, the labor process and dignity at work. Social Forces, 91, 1209-1238. doi:10.1093/sf/sot042

Das, A. (2009). Sexual harassment at work in the United States. Archives of Sexual Behavior, 38, 909-921. doi:10.1007/s10508-008-9354-9

DeJordy, R. (2008). Just passing through: Stigma, passing, and identity decoupling in the work place. Group \& Organization Management, 33, 504-531. doi:10.1177/1059601108324879

Dufur, M. J., \& Feinberg, S. L. (2007). Artificially restricted labor markets and worker dignity in professional football. Journal of Contemporary Ethnography, 36, 505-536. doi:10.1177/0891241606294120

Embrick, D. G., Walther, C. S., \& Wickens, C. M. (2007). Working class masculinity: Keeping gay men and lesbians out of the workplace. Sex Roles, 56, 757-766. doi:10.1007/s11199-007-9234-0

Fleming, P. (2005). "Kindergarten cop": Paternalism and resistance in a high-commitment workplace. Journal of Management Studies, 42, 1469-1489. doi:10.1111/j.14676486.2005.00551.x

Giuffre, P. A., Dellinger, K., \& Williams, C. L. (2008). ”No retribution for being gay?”: Inequality in gay-friendly workplaces. Sociological Spectrum, 28.

Hodson, R. (2001). Dignity at work. Cambridge, UK: Cambridge University Press.

Honneth, A. (1995). The struggle for recognition: The moral grammar of social conflicts (J. Anderson, Trans.). Malden, MA: Polity Press.

Human Rights Campaign. (2015). Corporate equality index 2016: Criteria updates \& toolkit for success. Washington, D.C.: Human Rights Campaign.

Hunt, R., \& Dick, S. (2008). Serves you right. London, UK: Stonewall.

Islam, G. (2013). Recognizing employees: Reification, dignity and promoting care in management. Cross Cultural Management: An International Journal, 20, 235-250. doi:10.1108/13527601311313490

Karlsson, J. C. (2012). Organizational misbehaviour: Narratives of dignity and resistance. London, UK: Palgrave Macmillan.

Kim, E. C. (2009). 'Mama's family': Fictive kinship and undocumented immigrant restaurant workers. Ethnography, 10, 497-513. doi:10.1177/1466138109347000

Lee, M. Y. K. (2008). Universal human dignity: Some reflections in the Asian context. Asian Journal of Comparative Law, 3, 283-313. doi:10.2202/19320205.1076

Lewis, A. P. (2006). Communicating lesbian identity: A critical analysis of popular culture representations and police officer narratives. Tempe, AZ: Arizona State University Press. 
Lewis, A. P. (2009). Destructive organizational communication and LGBT workers' experiences. In P. Lutgen-Sandvik \& B. D. Sypher (Eds.), Destructive organizational communication: Processes, consequences, and constructive ways of organizing (pp. 184-202). New York, NY: Routledge.

Lucas, K. (2011). Blue-collar discourses of workplace dignity: Using outgroup comparisons to construct positive identities. Management Communication Quarterly, 25, 353-374. doi:10.1177/0893318910386445

Lucas, K. (2015). Workplace dignity: Communicating inherent, earned, and remediated dignity. Journal of Management Studies, 52, 621-646. doi:10.1111/joms.12133

Lucas, K., \& Gist, A. N. (2015). Organizing social class: Implications for working-class dignity. Paper presented at the Academy of Management annual meeting, Vancouver, BC.

Lucas, K., Manikas, A. S., Mattingly, E. S., \& Crider, C. J. (2017). Engaging and misbehaving: How dignity affects employee work behaviors. Organization Studies. Advance online publication. doi:10.1177/0170840616677634

Mears, A., \& Finlay, W. (2005). Not just a paper doll: How models manage bodily capital and why they perform emotional labor. Journal of Contemporary Ethnography, 34, 317-343. doi:10.1177/0891241605274559

Meyer, E. J. (2009). Gender, bullying, and harassment: Strategies to end sexism and homophobia in schools. New York, NY: Teachers College.

Nadal, K. L. (2008). Preventing racial, ethic, gender, sexual minority, disability, and religious microaggressions: Recommendations for promoting positive mental health. Prevention in Counseling Psychology: Theory, research, practice and training, 2, 22-27.

Nadal, K. L., Rivera, D. P., \& Corpus, M. J. H. (2010) Sexual orientation and transgender microaggressions in everyday life: Experiences of lesbians, gays, bisexuals, and transgender individuals. In D. W. Sue (Ed.), Microaggressions and Marginality: Manifestation, Dynamics, and Impact (pp. 217-240). New York: Wiley.

Nadal, K. L. Issa, M., Leon, J., Meterko, V., Wideman, M., \& Wong, Y. (2011). Sexual orientation microaggressions: "Death by a thousand cuts" for lesbian, gay, and bisexual youth. Journal of LGBT Youth, 8(3), 1-26.

Otis, E. M. (2008). The dignity of working women: Service, sex, and the labor politics of localization in China's City of Eternal Spring. American Behavioral Scientist, 52, 356-376. doi:10.1177/0002764208325309

Ozturk, M. B. (2011). Sexual orientation discrimination: Exploring the experiences of lesbian, gay and bisexual employees in Turkey. Human Relations, 64, 1099-1118. doi:10.1177/0018726710396249

Pinsker, J. (2015). Unequal pay: The gay wage gap. The Atlantic. Retrieved from http://www.theatlantic.com/business/archive/2015/06/gay -men-women-lesbian-earnings-wage-gap/396074/

Rubin, H. J., \& Rubin, I. S. (2005). Qualitative interview: The art of hearing data $\left(2^{\text {nd }}\right.$ ed.). Thousand Oaks, CA: Sage.

Rumens, N., \& Kerfoot, D. (2009). Gay men at work: (Re)constructing the self as professional. Human Relations,62, 763-786. doi:10.1177/0018726709103457
Sanders, C. R. (2010). Working out back: The veterinary technician and "dirty work". Journal of Contemporary Ethnography, 39, 243-272. doi:10.1177/0891241610366711

Sayer, A. (2007). Dignity at work: Broadening the agenda. Organization, 14, 565-581. doi:10.1177/1350508407078053

Sayer, A. (2011). Why things matter to people: Social science, values and ethical life. Cambridge, UK: Cambridge University Press.

Sears, B., \& Mallory, C. (2011). Documented evidence of employment discrimination and its effects on LGBT people. Los Angeles, CA: The Williams Institute, UCLA School of Law.

Silverschanz, P., Cortina, L. M., Konik, J., \& Magley, V. (2008). Slurs, snubs, and queer jokes: Incidence and impact of heterosexist harassment in academia. Sex Roles, 58, 179-191. doi:10.1007/s/11199-007-9329-7

NY: Holt, Rinehart and Winston.

Stuesse, A. C. (2010). What's 'justice and dignity' got to do with it?: Migrant vulnerability, corporate complicity, and the state. Human Organization, 69, 19-30. doi:10.17730/humo.69.1.886106412v421152

Sue, D. W. (2010). Microaggressions in everyday life: Race, gender, and sexual orientation. New York, NY: Wiley.

Waite, S., \& Denier, N. (2015). Gay pay for straight work: Mechanism generating disadvantage. Gender and Society, 29, 561-588. doi:10.1177/0891243215584761

Watson, T. J. (2008). Managing identity: Identity work, personal predicaments and structural circumstances. Organization, 15, 121-143. doi:10.1177/1350508407084488

Yoshino, K. (2006). Covering: The hidden assualt on our civil rights. New York, NY: Random House. 